\title{
MedienPädagogik
}

$w w w$. medienpaed.com

Zeitschrift für

Theorie und Praxis

der Medienbildung

ISSN 1424-3636

Themenheft Nr. 19: Mobile Learning in Widening Contexts: Concepts and Cases

\section{Experiences with an Online Mobile Learning Platform Intervention for Marginalised Young People}

Elisabeth Unterfrauner, Ilse Marschalek and Claudia Magdalena Fabian

\begin{abstract}
Marginalised young people who find themselves disadvantaged in a number of respects also tend to experience limited access to Information and Communication Technologies (ICT) - with the exception of mobile phones. The European Commission-funded Comeln project ${ }^{1}$ seeks to take advantage of marginalised young people's access to mobile phones by reaching out to them via an innovative pedagogical approach based on the media convergence of the mobile phone through an online platform with video streaming. The platform was developed specifically for the purposes of the project to create the possibility for new, positive learning experiences as well as for interaction with peers and youth workers. In a threemonth study in Austria and the United Kingdom, 94 young people accessed the platform via their mobile phones. In this paper we discuss the appropriateness of media convergence as a means for learning in and across three dimensions: interaction, creative expression and self-organisation. Furthermore, we explore how to incorporate initiatives such as Comeln in an institutionalised context.
\end{abstract}

\section{Introduction}

The 16 years old Mirko was born and raised in Vienna in a Roma community. Although he is functional illiterate he managed to complete secondary school but since leaving school two years ago he has been inactive in terms of looking for a job or continuing education. Daria, 17 years old, has been seen by psychiatrists several times and her diagnoses range from depression to anxiety disorders and abnormal social behaviour. She grew up in different foster families and currently lives in a children's village. She dropped out of school once she had completed compulsory education and left without qualifications. Mirko and Daria might be called marginalised young people as for different reasons they stand at the margins of society and are at risk of being excluded.

Marginalised young people are disadvantaged in a number of ways, including in terms of reduced access to ICT such as the Internet. They, therefore, face a socalled Digital Divide, i. e. a gap between the «information rich» and the «information poor» depending on whether they have access to modern media (cf. Norris, 2001; Yu, 2006). While this gap clearly affects marginalised young people, their access to mobile phones is not affected that much (Livingstone \& Helsper, 2007).

1 http://www.comein-project.eu/ 
On the contrary, for marginalised young people mobile phones are of particular relevance and offer them features that support access to information and networks (cf. Pachler, Cook \& Bachmair, 2010).

The EU-funded Comeln project - Online Mobile Communities to Facilitate the Social Inclusion of Young Marginalised People - aims to study factors contributing to marginalisation and to alleviate some of these by developing an online mobile learning platform tailored to the needs of the target group. This intervention is expected to some extent to contribute to interrupting the vicious circle of marginalisation of young people who have already dropped out of school or do not proceed education or employment after compulsory school graduation.

\section{Marginalised young people}

Today's youth is considered by many researchers as «being at risk» during their transition to adulthood: «The terms risk and youth have become synonymous, and young people are increasingly perceived as either «at risk〉 or as 〈posing a risk»» (Armstrong, 2004; Goldson, 1999; Swadener \& Lubeck, 1995; as cited in Kemshall, 2008 , p. 22). In modern societies, this transition process has become longer and more complicated as a result of the extension of secondary education, accompanied by the diversification and individualisation of social life, corresponding to what sociologists call "diversification of pathways into adulthood» (Biggart, Bendit, Cairns, Hein \& Mörch, 2004, p. 13). However, certain groups of young people can be seen as being more at risk of social exclusions than other groups. Young people who have to contend «with a plurality of obstacles in attempting to make transitions into adulthood, but have relatively few resources with which to do so» (Parry, 2006, p. 296) are defined as marginalised young people or «at risk» youth or simply as young people with fewer possibilities.

Contributing factors that can be identified in studies about marginalisation processes among young people comprise six distinct dimensions (cf. Brüning \& Kuwan, 2002; Kieselbach, Heeringen, Lemkow, Sokou \& Starrin, 2001; Nyyssölä, 1999; Kritikos \& Ching, 2005): labour market-related, economical, cultural, social, geographical and institutional dimensions. Brüning and Kuwan (2002) argue that social exclusion is probable if a person is affected at least on three of these dimensions. According to Wagner, Gerlich and Gebel (2008) marginalisation occurs as interaction of factors on different levels: on the micro-level (e. g. personal premises, talents and interests), on the meso-level (e.g. social milieu, status, family) and on the macro-level (e.g. structural conditions, societal values and norms). Disadvantages are interlinked and clustered and only when a young person «has a weak position in a number of arenas simultaneously can we talk of marginalisation» (Heggen, 2000 , p. 48). Thereby factors that lead them into marginalisation and symptoms 
of marginalisation that has already taken place are interchangeable, making the process of marginalisation a vicious circle which is difficult to break.

\subsection{Marginalised young people and digital media skills}

Young people affected by marginalisation do not only experience the digital divide in terms of diminished access to ICT but also their preferences and their media skills are different from other youths. Thus, the scientific as well as policy discussion has moved from the «digital divide» to the «participatory divide» (Biermann, 2009) resulting in an increasing demand for specific pedagogies and educational offers for marginalised young people besides providing mere access. New pedagogical concepts are needed that tie in with daily media experiences and interests of marginalised young people and at the same time reduce the reproduction cycle of social inequity to some extent as Biermann (2009) postulates.

Similar to their peers, marginalised young people make extensive use of their mobile phones. Most, however, do not use further information and communication technologies on a regular basis. This does not imply that they would reject them altogether but it has to be seen in light of, to some extent, limited reading and writing (literacy) skills among marginalised young people and the fact that many communities and features seem to be too complex and too text-orientated for them (cf. Bachmair, Pachler \& Cook, 2009). The project Comeln has dedicated itself to finding a way to building on individual skills of marginalised young people and to offer new positive learning experiences that enable them to create their own content and not solely reduce them to content consumers.

\subsection{Target group of Comeln}

Mirko and Daria are two of the 94 young people who participated in the three months long Comeln pilot.

The pedagogical approach as well as the technological development of the online platform in Comeln were specifically developed for young people such as Mirko and Daria, i.e. young people between the ages of 14 and 21 who are neither in employment nor education, thus who have been inactive for at least six months and who experience difficulties in entering into the labour market or in proceeding with their educational activities for whatever reasons. Thus, the target group in focus is marginalised on two specific, but significant dimensions: education and economy, i. e. young people with educational and income-determined barriers. Both, Mirko and Daria, have been visiting a youth organisation in Vienna that supports them in employment seeking activities and offers them internships to get some work experience. Youth workers who had been working with Mirko and Daria asked them to take part in the Comeln project. Similarly, the young people who finally participated in the pilot were in contact with a youth organisation in the UK or in Austria and were approached by youth workers to take part in the Comeln pilot. 
Participants came from different regions of the UK and Austria and had a balanced distribution of age and gender as Table 1 shows.

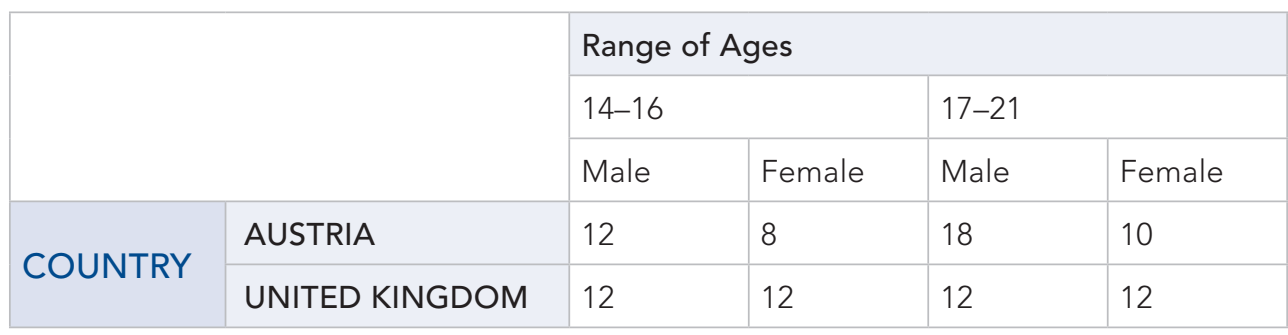

Table 1: Sample of participants by country, gender and age range

The sample of 94 young marginalised young people had the following characteristics': their highest educational level was low or medium with corresponding low to medium literacy and numeracy skills levels. Most of the participants had dropped out of school before completing secondary school or had quit education after completion of secondary school. Some reported they had made negative experiences at school such as not feeling competent enough in comparison to other pupils or they simply expressed their wish to work instead of continuing with their education.

The life circumstances and attested diagnoses differed among the participants. Most of them still lived with their families but often lacked an important reference person in their homes and did not get much support by family members. Some young people reported cognitive impairments such as Asperger syndrome, functional illiteracy or learning difficulties. Others were diagnosed with a personality disorder, depression, anxiety disorder or another psycho-social disorder.

In terms of ICT interest, they preferred mobile phones and had medium ICT competences. In terms of relationships, most of the participants had not known other people in the sample before.

The pilot participants were diverse in terms of the difficulties they experienced in their lives but all shared the status of «inactivity» in terms of engagement in employment and education and showed an interest in ICT and in the Comeln project.

2 Data was gathered through semi-structured interviews with pilot participants and youth workers. 


\section{The pedagogical approach}

One step towards social inclusion is to undergo positive learning experiences and thus (re)engage school dropouts in learning processes. For marginalised young people those experiences have to be outside of the formal education system and have to happen in alternative forms to traditional ways of teaching at school. Thus, one of the demands for a new pedagogical approach is to make use of the fun aspect of young people's devices, using attractive means of ICT, and extend their interests from pure consumption of content to the creation of content. The idea was to invite them to make use of tools they like and know. By means of the mobile phone and a simple audio-video based communication approach, they could express themselves in media they knew and were familiar with and decide when and where they would take part in a self-determined learning process. The learning goal for the participants of the project was to promote basic skills required by the labour market in terms of interaction (social norms and behaviour), creative expression (self-reflection and self-regulation) and self-organisation.

\subsection{A mobile community platform tailored to the needs of the target group}

The Comeln project developed an online mobile community platform, i.e. an online video stream-based platform that gathers community features and can be accessed via mobile phones, resulting in a media convergence of «mobile phone», «online community» and "video» as media format. To engage young marginalised people in this self-determined community and in collaborative informal learning processes a simple pedagogical concept was worked out. The platform developed for the purposes of the project aimed at reflecting the needs of the target group and offering them a protected zone only registered pilot participants could enter. Although community platforms which can be accessed via mobile phone are already available, e.g. Facebook, these would not have supported our purposes as the project inter alia required a restricted platform. Based on the results of an extensive literature review and a user requirement analysis the Comeln platform was developed. For instance, the platform had to be based on visual communication so that even people with limited or restricted literacy skills such as Mirko were able to participate. For young people such as Daria easy navigation across the platform was crucial as she had experienced information overflow in other social networking sites. Thus, the platform developed was characterised by a simple and clear user interface with some basic features that supported the main target activities of participants (cf. Figure 1). They could create their own profiles and engage in several community activities: a personal account with a nick name, a photo and individual settings, the possibility to create, moderate and join groups, the possibility of sending messages via the platform, add favourites, and above all, special features for video communication, such as streaming, uploading, replying to and rating of videos. 


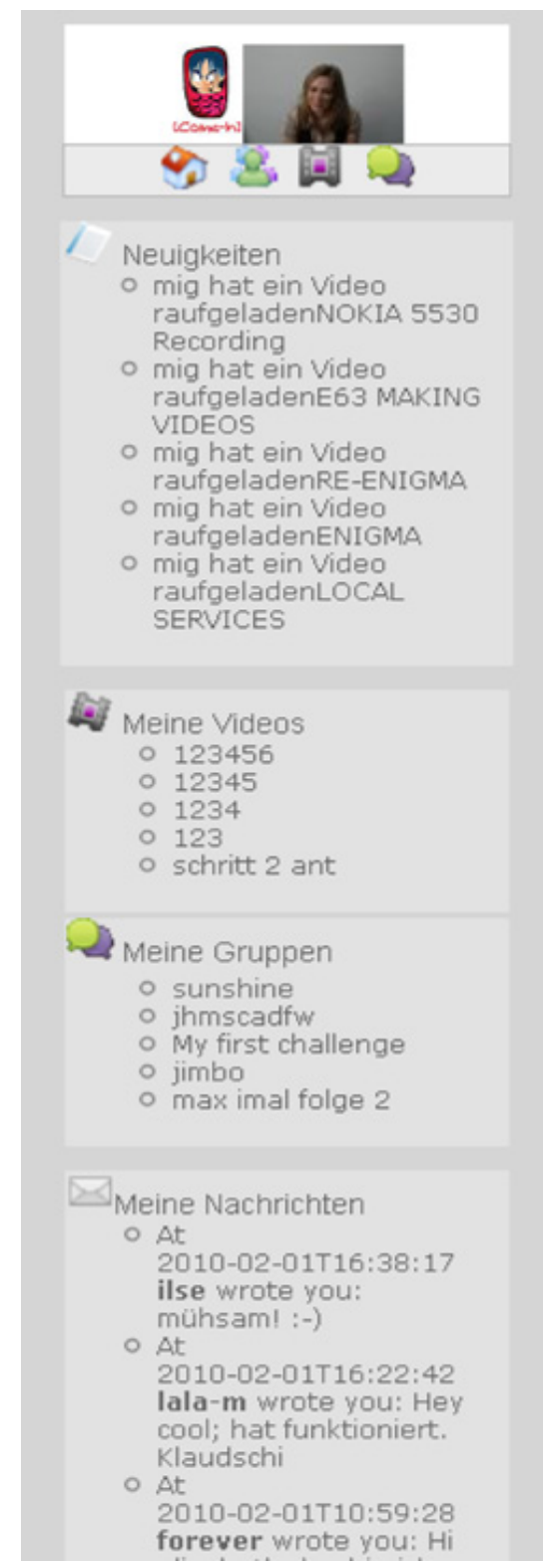

Figure 1: Screenshots of Comeln platform: user site
Thus, most of the communication on the platform was meant to be based on short videos which could be created with the built-in cameras of their mobile phones and be immediately uploaded to the platform via a $3 \mathrm{G}$ connection.

\subsection{Video-ping-pong approach}

To enhance interactivity on the platform and to stimulate contributions of pilot participants a reciprocity concept was chosen as the main communication channel, the so-called pingpong approach promoting the exchange of self-made videos. As marginalised youths are rather challenged by tasks that require self-organisation and self-regulated learning (Kritikos \& Ching, 2005), moderator roles as personal guides were introduced to the platform. Youth workers with a long experience of working with marginalised young people were chosen as moderators of the platform and they further supported the research team in working out the pedagogical concept. In total eight youth workers were trained and engaged as moderators on the platform. Their role was to stimulate participation of the young people, to support them in case of problems or questions being raised, to safeguard netiquette rules on the platform and to provide feedback. Furthermore, they were asked to keep a diary on all the interventions (which could take place directly on the platform, or via text messages, calls or face-toface). The research team, together with the moderators, created "challenge videos» which contained learning tasks about personal development and skills relevant in employment. For each of the 12 learning steps several challenge videos were produced and uploaded to the platform by the moderators on a weekly basis.

The idea of the challenge videos was, on the one hand, to provoke self-reflection on specific topics, such as in step 1 to reflect on one's skills or in step 4 how to motivate oneself (cf. Table 2). On the other hand, the videos aimed at stimulating interaction among participants so that they would comment on each other's ideas referring to the challenge videos and exchange their thoughts.

Daria, for instance, created a video referring to learning step 1, i. e. self introduction, showing one of her favourite activities singing and dancing - and received feedback from other peers in the form of positive ratings and comments. Responding 


\begin{tabular}{|l|l|}
\hline 1 & Self introduction \\
\hline 2 & $\begin{array}{l}\text { Job and other activity } \\
\text { portraits }\end{array}$ \\
\hline 3 & Self organisation \\
\hline 4 & Motivation \\
\hline 5 & Job application \\
\hline 6 & Keeping a job, job routine \\
\hline 7 & Difficulties, rights and duties \\
\hline 8 & $\begin{array}{l}\text { Communication and social } \\
\text { competences }\end{array}$ \\
\hline 9 & Dealing with Money \\
\hline 10 & Help and support \\
\hline 11 & Health aspects \\
\hline 12 & Strategies and future steps. \\
\hline
\end{tabular}

Table 2: Learning steps overview to learning step 4, Mirko broadcast himself, speaking directly into the camera presenting several ideas how to motivate himself (such as rewarding himself when he had accomplished something).

All challenge videos followed a simple script which embedded it in an engaging story and a task or a question to solve. The challenge videos were no more than 40 seconds long and were produced without editing and without any further equipment besides the build-in camera of the mobile phone. Different "characters» performed in these challenge videos: youth workers, young people, puppets and animals. For instance, in one of the challenge videos referring to learning step 4 , which deals with self-motivation, one of the youth workers, who also acted as moderator on the platform, tries to motivate a dog who is lying down on the floor and does not move. At the end she succeeds and poses the following question to the camera: "When you have a bad day how do you motivate yourself?» (see Figure 2).

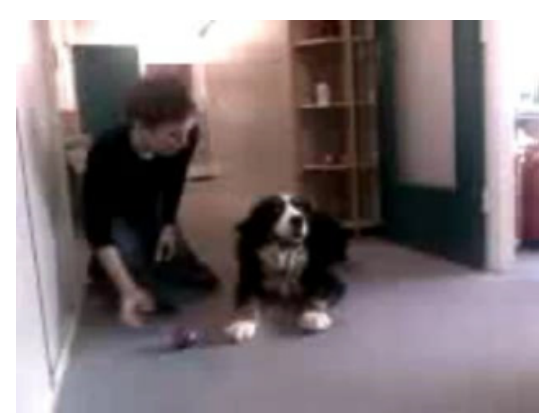

Figure 2: Challenge video for learning step 4

The twelve steps were sequenced in a way that tasks became more complex or challenging later on in the pilot. Every week several challenge videos that all referred to the same learning step were uploaded and participants were free to react to these by producing a video with their answer or solution allowing for a self-determined learning process. Their answer video, in turn, then received a feedback video created by the moderators or by other young people resulting in videos that related to each other which the research team called the video-ping-pong approach as depicted in Figure 3. 


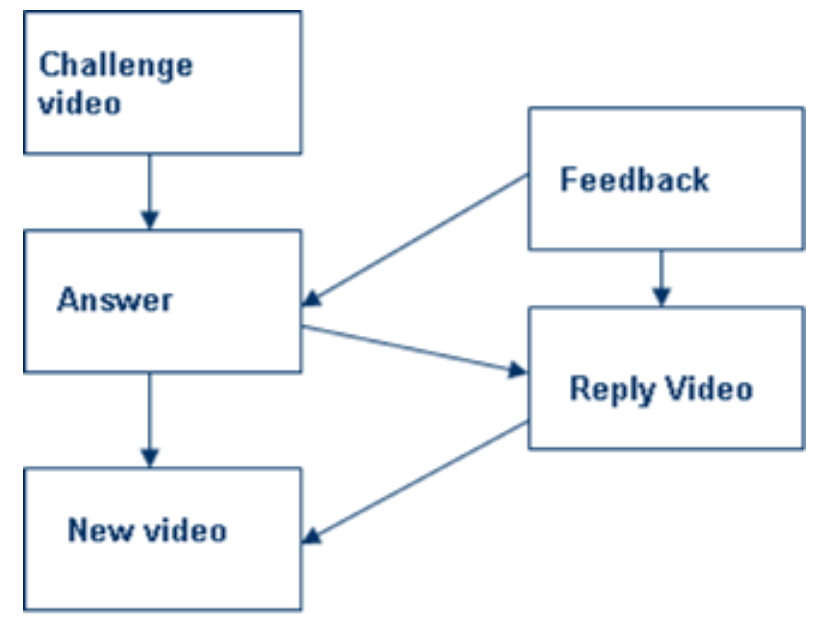

Figure 3: Video-ping-pong approach

All challenge videos were created in order to stimulate participation of the young people but did not have a mandatory character. Neither was the answer video predefined. Participants could create answer videos on their own, collaborate with others, simply speak into the camera, «act» or record something. Participants could also create their own challenges or relate their videos to those by other participants. Ideally, there were answer videos to challenge videos and reply videos by other participants to answer videos. Furthermore, the platform members could use all the features of the platform to relate to others: send text messages, share videos, rate videos, create groups on a specific topic and subscribe to groups that have been created by others.

\section{Comeln pilot study in focus}

For the pilot phase the participating marginalised young people were provided with a mobile phone and an appropriate package of provider offers to allow for active pilot participation free of cost. During face-to-face introductory sessions in different regions, participants were introduced to the study and committed themselves to the pilot and the platform netiquette rules. During these introductory sessions, participants could also experience the first platform activities and, in an interactive way, learn how to make videos with the mobile phone, upload them to the platform and use all features of the online mobile learning platform.

During the pilot the moderators then uploaded the challenge videos according to the learning step schedule and provided feedback videos for all those who had responded to the challenge video (see Figure 4). 
An intermediate face-to-face meeting gathered preliminary feedback from participants and some suggestions for improvement. During the pilot period, participants were in regular contact with the moderators, either via the platform, by phone or face-toface. During concluding face-to-face sessions, the mobile phones they had already used during the pilot were given to them as reward and participants received a certificate for their successful participation which they could attach to their job applications.

\subsection{Evaluation methodology}

Pilot activities provided a range of different data to be collected at different stages of the pilot phase. Data from the following sources were analysed:

- Direct contact with the participants (focus group discussions, interviews, video feedback questions)

- Direct contact with moderators (interviews, group interview³)

- Documentation and pilot diaries of moderators

- Log-data of users on platform

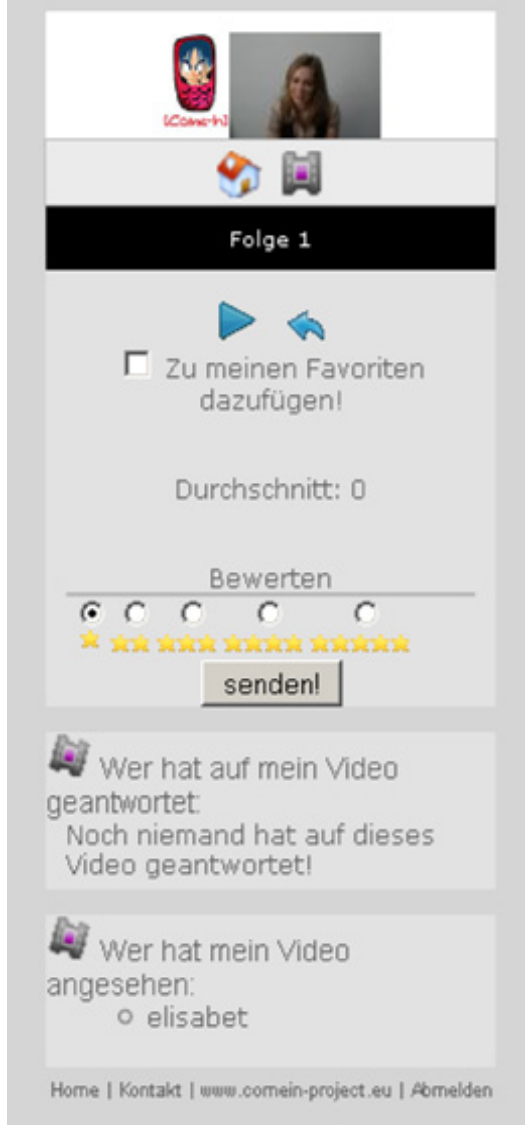

Figure 4: Screenshots of Comeln platform with uploaded challenge video

- Platform activities (messages, groups, ratings, etc.)

The basis for the analysis of the pilot results was a triangulation of qualitative and quantitative methodologies carried out based on the different data sources. Qualitative analysis was worked out of transcripts of group discussions and interviews which were conducted at an intermediate stage and at the final stage of the pilot phase. Based on log-data, quantitative analysis showed all relevant numbers of participants' activities, such as time spent online, number of uploaded videos, number of watched videos, etc. A social network analysis showed different forms of interactions between pilot participants. For the artefact analysis of platform videos, an external team of three experts of different representative fields (media

3 The authors refer to the interview and focus group data gathered solely in Austria. Thus due to the limited availability of data in case of the UK participants, in this article, comparisons between the two pilot sites were avoided. 
pedagogy and evaluation) screened 160 uploaded videos (80 from the UK Pilot and 80 from Austria), including feedback videos created by pilot participants.

\section{Results}

This paper explores the impact of the pedagogical approach based on media convergence of «mobile phone», "online community» and «video» as media format along three different dimensions of learning that might have occurred among the pilot participants: interaction dimension (social norms and behaviour), creative expression dimension (self-reflection and self-regulation) and self-organisation dimension.

The results are based on various sources of data as described above. Besides reacting to challenge videos, the young people benefited from their participation through their creative use of the platform as will be shown.

\subsection{Interaction dimension}

In the three months long pilot the community slowly developed and became vivid and lively with increasing interactions between its members, both between peers as well as between moderators and young participants. In total, the community uploaded 585 self-created videos to the platform which were viewed 3,759 times and rated another 508 times. Additionally, community members exchanged 1,983 personal messages and posted another 722 messages in groups. In total, they created 66 groups that all had a specific topic which were filled with videos as well as messages. These groups were subscribed 639 times and dealt with diverse topics that ranged from «childhood memories» or «hairdressing» to «kids having kids» or "school dayzzzz». By means of creating a new group, young people had the possibility to interact and exchange ideas about specific topics that were of interest and relevance to their lives.

The social network analysis, a method, that allows interaction between members of a community to be demonstrated, shows that the different pilot participants have acquired different roles on the mobile online learning platform. Some have central positions, i.e. they function as connectors between other people and are strongly tied to others in terms of exchanged personal messages, while others rarely communicate with others using textual exchange. In Figure 5, each participant is represented as a yellow circle with their given ID number to preserve anonymity while the size of the circle correlates to the number of messages sent. The black lines show exchanged messages between two specific participants. Again, the size of the line represents the number of messages sent and received. As a whole, the social network analysis reveals a good level of reciprocity (67 MYPs are in reciprocal contact) which means that both the sender and the receiver of the text message are interested in communication and able to connect to the Comeln platform. 


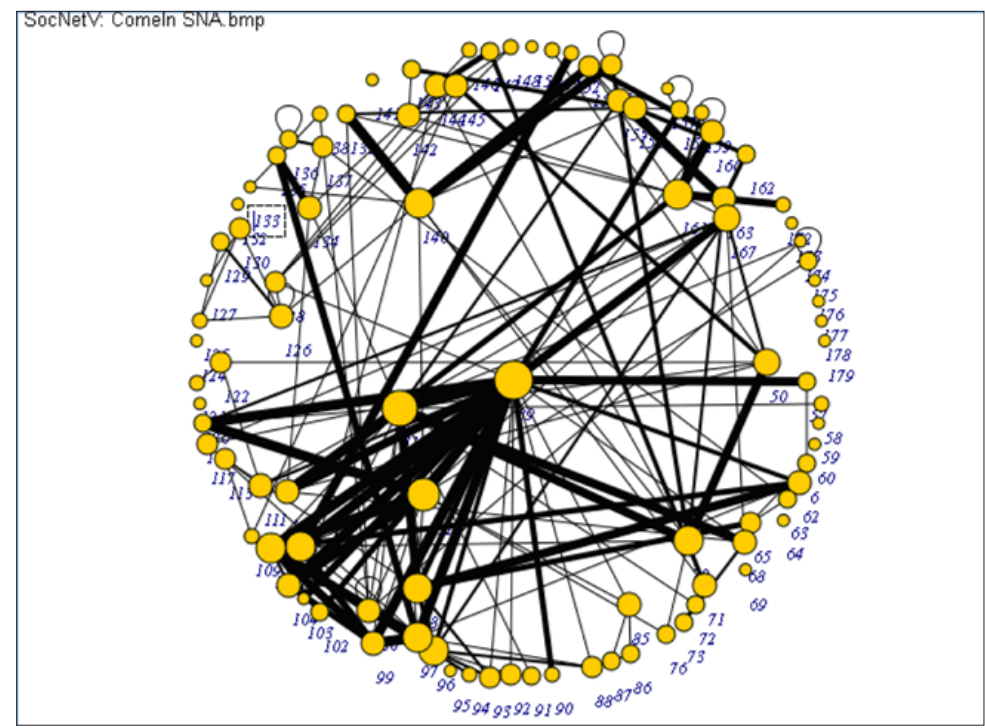

Figure 5: MYP-to-MYP network during pilot in terms of personal messages

Daria became a heavy exchanger of messages in the community. She is at the very central position of the network in Figure 5, having very strong ties to many other community members. She contacted many other young people on the platform and got many messages in return. Even language barriers did not keep her from contacting participants in the UK, instead she engaged in communicating in English and helping other participants to communicate in the foreign language.

Others did not use the messaging function as frequently but preferred videobased communication instead. Mirko, for example, who due to literacy problems was not able to write or read textual messages, uploaded many videos and reacted to others' videos to express his ideas and to comment on others.

"To make new friends» and to "get to know people from abroad» were the most popular motivators to take part in the community that emerged during the focus groups with the participants. The platform supported various communication styles and skills as the pilot experience shows. It was seamlessly used by people with different mother tongues, by people with literacy problems as well as people with Asperger syndrome or with an antisocial personality disorder. Depending on their skills, they chose visually-based communication or text-based communication. In the first case, people who relied more on visually-based communication, would rather have accessed videos and commented on the videos of others while in the second case, people with an emphasis on text-based communication, chose to send messages or to post messages in a group.

Not only did the young participants benefit from the interaction with peers but they also benefited from the interaction with the moderators. They could contact the moderators at any time and did not have to wait until the next face-to-face- 
meeting. Conversely, the moderators could get in touch with young people they were worried about or who had not contacted the youth organisation for some time. Also, they appreciated the platform as an additional channel for communication and to get to know the young people better as well as to use that information as ice-breaker in face-to-face contacts as the moderators mentioned in interviews.

\subsection{Creative expression dimension}

As Mirko has poor literacy skills, shooting videos was the perfect way for him to express himself. Mirko loved presenting himself in front of the camera sharing daily experiences and let others get some insights into his life. For instance, Mirko recorded a wedding in the Roma community; another video showed a person playing a typical Roma instrument. Mirko recorded his neighbourhood, his room, his favourite objects, his personal belongings and introduced family members and friends in the form of videos posted to the online community. Daria used the platform like a diary. Almost every day she recorded a video and uploaded it to the platform. Most of the time, she recorded herself speaking directly into the camera sharing her thoughts on different topics such as first impressions at a new internship placement.

As previously mentioned, the pilot participants took advantage of the different channels of communication depending on their skills and interests. The participants similarly adopted the video-ping-pong approach for creative self-expression as the in-depth analysis of videos created by the Austrian participants, which were more closely analysed, reveals. Table 3 shows that out of 231 videos from the Vienna pilot, $84 \%$ were self-made with the built-in camera of the mobile phone and only $1 \%$ were taken from the mobile phone (some videos were already available on the mobile phone), while $14 \%$ of the videos were video clips filmed from the Internet, from television or video games.

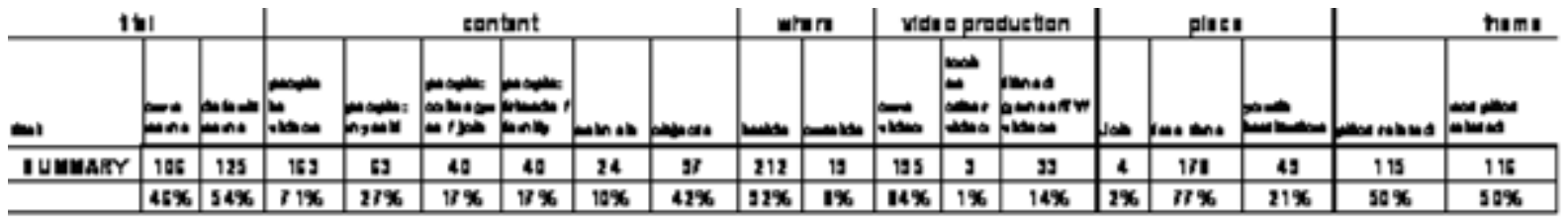

Table 3: Summary of uploaded videos of the Viennese participants

Interestingly, $92 \%$ of the videos were taken inside and only $8 \%$ were taken outside, which could be interpreted in a way that the most relevant issues in their lives are related to indoor activities or that filming outside can sometimes be rather challenging with background noise that are difficult to control.

One of the videos uploaded referring to learning step 3, self organisation, that had been taken outside, showed a finger moving around the metro map of Vienna demonstrating how to reach specific locations across the city. An example of a 
video which was taken inside shows two participants playing roles in a typical job interview situation as reaction to learning step 5 (job application). The videos were mainly taken during participants' free time $(77 \%)$, only $21 \%$ show the surrounding of their youth institution and $2 \%$ represent a job situation (some of them did an internship during the period of the pilot and were often not allowed to use their mobile phones during working hours). In one video one of these interns shares her experience at McDonalds where she had been working for some days.

Half of the videos uploaded directly related to the pilot and the challenge videos on the Comeln platform and half of them were not specifically linked to them. Around $46 \%$ of the analysed videos were given a specific name, while in $54 \%$ of cases the default name was kept (a long number which was assigned by the mobile phone). These proportions have to be interpreted in the light of the limited literacy skills of some participants and of the default setting of the mobile phones. The analysis of the video contents reveals how the participants introduced themselves to the community. Around $71 \%$ of the videos show other people, $27 \%$ show themselves, $17 \%$ colleagues, $17 \%$ friends and family, $10 \%$ animals and $42 \%$ objects. Obviously, more than one of these categories could be present in one single video. They either liked to present themselves by speaking into the camera or asked their moderators or peers to introduce them. One young person used the hero of his favourite video game and produced a voiceover to introduce himself. Other young people preferred to film their own rooms or favourite objects, such as motorbikes and furniture. The television was a recurrent object in the videos and obviously was of high relevance for some participants who filmed the family watching television together. Others presented their favourite animals such as horses, cats, dogs and fish or family members like mother, father, brother, sister and friends. Some videos showed a creative dramaturgy. For instance, one boy described the preparation of a dish in the kitchen of the youth institution like a football game commentator or a girl introduced herself as a "cloud» by jumping in a container full with leaves. In the interviews, the participants pointed out that the most popular topics were friends - especially boyfriends, animals, hobbies and favourite locations. Out of 24 participants interviewed, only two underlined that they did not like to take videos at all and one girl stressed that she was too afraid to put a video on the Comeln platform.

As the log-data reveals, the number of videos uploaded varied among the participants with the highest number being 55 and the lowest being zero. The videoanalysis of the independent experts confirms the results from the Austrian pilot. According to them, the most frequent content was related to daily-life activities and home-settings. Entertaining elements such as video-games and television as well as the observation of relevant places, family and friends were represented. According to the experts, words did not have an important role in their creation. 
Besides making use of self-made videos, the participants also expressed their creativity through the creation of groups on the platform. The analysis of the creation of groups shows that older females were the most active users in creating new groups and subscribing to groups, while young males were less engaged in these activities.

\subsection{Self-organisation dimension}

One conclusion drawn by the external team of three experts who were invited to screen a considerable number of videos uploaded was that the participants improved their skills in video recording, especially in talking in front of a camera. Their self-expression skills were judged to have improved significantly and to have become clearer towards the end of the pilot. With the possibility to create their own videos and to present these to a wider audience via the Comeln online community, they were stimulated to practise their ICT competences by having to handle technical obstacles which occurred from time to time and working out solutions alone, with friends or with the help from moderators. According to the moderators, the level of frustration tolerance (i. e. the individual ability to handle frustrating moments)was surprisingly high in comparison to other situations where the young people had to face challenges.

In the interviews with the participants of the Vienna pilot, 10 out of 24 young people admitted that they had asked for help with taking a video or uploading it to the Comeln platform. Six of them had received support from their moderators at the youth institution, three from their best friends and one from his family. The other 14 participants underlined in their interviews that they had not needed any help from others and that the access to the Comeln platform had been easy and intuitive.

Compared to other activities on the platform, the reaction to challenge videos in form of uploading answer videos was somehow limited. Nevertheless, the analysis of the answer videos uploaded as well as the interviews and focus group discussions reveal that self-reflecting processes had been stimulated in the community as participants talked about their experiences and the challenge to reflect on issues of what to reveal about oneself and also what might be of interest for others. According to the moderators, communication skills and self-esteem among some participants improved during the pilot and some got encouraged because of their participation in the pilot. Mirko, for instance, was known as a rather passive young person who was difficult to engage. However, on the platform he was the one to upload the most videos and the youth workers noted that in group activities at the youth organisation he also became more active.

Through the challenge videos and the use of the Comeln platform the communication between the moderators and the young people was strengthened and it helped them to understand them more deeply and how they were able to support them better. The participants had the chance to learn not only from the feedback 
of the moderators but also from their peers, who gave helpful comments on the platform or during several formal and informal meetings.

Apart from learning to produce videos, the participants had to respect the common netiquette on the Comeln platform. The netiquette consisted of ten rules, such as respecting the privacy of others or encouraging others to participate. These rules regulated the communication and interaction on the platform and ensured a safe and valuable online environment for all participants. The participants had to reflect on their own contributions - video, text-messages, and group creation and whether they adhered to the agreed netiquette.

After the pilot, 20 out of 24 interviewed young people stated that they could imagine studying with videos. Although some showed a critical attitude towards learning on a mobile phone instead of learning in traditional learning settings, at the same time they were quite open towards this way of learning. The video format was easy to understand and for some of them it was much easier to listen to somebody instead of reading content. They found the video format engaging as it combines learning aspects with entertainment. The other four participants were still quite sceptical about this kind of learning. The experts observed in the video analyses that the mobile phone as an inherent element in the daily life of most participants had become a tool for learning, communication and self-expression.

\section{Conclusion, limitations and recommendation}

Mirko and Daria both enjoyed taking part in the Comeln pilot as they found a way of expressing themselves as well as an additional and protected zone for communication and the exchange of ideas with peers and with the youth workers.

The results suggest that the intervention based on the media convergence of «mobile phone», "online community» and "video» as media format among marginalised young people has been successful in terms of skills improvements on the part of participants in all three dimensions analysed, i.e. interaction, creative expression and self-organisation, although a longer pilot to measure long-term effects is necessary to validate the results. Particularly, for the measurement of changes in soft skills a longer observation period is required. Our study has also confirmed that a community needs time to evolve and that an established sense of the community further stimulates the creation of self-generated content among its members (cf. Preece \& Maloney-Krichmar, 2003).

Although the pedagogical approach had been well prepared and had been worked out in an interdisciplinary team, the technical implementation in the form of the video-ping-pong-structure was somewhat limited which made it difficult at times for participants to identify challenge videos. Thus, on a platform that is based on the video-ping-pong approach a much clearer structure would be needed. Furthermore, an institutional implementation would guarantee sustainability of the intervention. It could be taken up by youth organisations working with margina- 
lised young people or in labour market measures but also the adoption in a school environment is possible. It could serve as preventative measure for at-risk learners who might drop out of school. Thus, the mobile learning-based intervention could be adopted to further contexts and learning environments. However, in any institutional implementation training of secondary users, such as youth workers or school teachers, including the handling of the technology and their role as moderators on the platform, is key.

The video-ping-pong approach could be applied to different learning aims, for instance, to discuss topics and to learn from each other. Thus, the platform supports collaborative leaning where some pupils could act as peer facilitators.

Furthermore, the Comeln platform addresses more than one sensory channel, as it combines textual with audiovisual material. The actual shooting of videos requires tactile-kinaesthetic perception and handling of objects and thus it supports different learner types. To have a virtual stage fostering personal creativity and self-expression might have a stimulating effect and provoke positive learning experiences with flow character (Csikszentmihalyi, 2008). According to this notion, in a stage of flow, people are fully immersed in their activities and experience deep enjoyment, creativity and complete involvement with life. When people experience flow their attention is completely focused and the working or learning procedures themselves are sufficient as sources for motivation, no external motivators are required. Introducing the mobile learning platform and community to a school environment would imply to «break through» the walls of classrooms as the community would not have to be confined to the pupils of one class but could comprise whole schools or even schools in different countries. Specific groups within the community could be created to discuss specific experiences such as excursions that could be shared with others.

The ideas discussed above show the potential of further work with marginalised young people and the flexibility of the platform and the video-ping-pong approach allows for implementation in different learning scenarios, settings and aims.

\section{References}

Armstrong, Derrick (2004). A risky business? Research, policy, governmentality and youth offending. Youth Justice 4(2), 100-116.

Bachmair, Ben; Pachler, Norbert; Cook, John (2009). Mobile phones as cultural resources for learning - an analysis of mobile expertise, structures and emerging cultural practices. MedienPädagogik 13.3.2009: www.medienpaed.com/2009/ bachmair0903.pdf

Biermann, Ralf (2009). Die Bedeutung des Habitus-Konzepts für die Erforschung soziokultureller Unterschiede im Bereich der Medienpädagogik. MedienPädagogik 17 (14.8.2009): www.medienpaed.com/17/biermann0908.pdf 
Biggart, Andy; Bendit, René; Cairns, David; Hein, Kerstin; Mörch, Sven (2004). Families and transitions in Europe. Directorate K - Knowledge-based economy and society. Unit-K.4 - Research in the social sciences and humanities.

Brüning, Gerhild; Kuwan, Helmut (2002). Benachteiligte und Bildungsferne - Empfehlungen für die Weiterbildung. Bielefeld: Bertelsmann Verlag.

Csikszentmihalyi, Mihaly (2008). Flow: The psychology of optimal experience. London: Harper Perennial.

Goldson, Barry (1999). Youth (in) justice: Contemporary developments in policy and practice. In Barry Goldson (Ed.), Youth Justice: Contemporary policy and practice. Aldershot: Ashgate. 1-17.

Heggen, Kare (2000). Marginalisation: on the fringe of the periphery - Youth as a risky life stage? Young 8, 45-62.

Kemshall, Hazel (2008). Risks, rights and justice: Understanding and responding to youth risk. Youth Justice 8(21), 22-37.

Kieselbach, Thomas; Heeringen, Van Kees; La Rosa, Michele; Lemkow, Louis; Sokou, Katerina; Starrin, Bengt (Eds.). (2001). Living on the Edge - An Empirical Analysis on Long-term Youth Unemployment and Social Exclusion in Europe. YUSEDER publications, Psychologie sozialer Ungleichheit (Vol. 11). Opladen: Leske + Budrich.

Kritikos, Eliza; Ching, Charlene (2005). Study on Access to Education and Training, Basic Skills and Early School Leavers (Ref. DG EAC 38/04). Lot 3: Early School Leavers. Final Report. London: European Commission DG EAC.

Niesyto, Horst (2009). Digitale Medien, soziale Benachteiligung und soziale Distinktion. MedienPädagogik 17 (24.6.2009): www.medienpaed.com/17/niesyto0906. pdf

Nyyssölä, Kari (1999). Youth Unemployment and Marginalisation - Changes in the Labour Market Status of Finnish Young People in the Years 1980-1993. Youth 7(2), 2-20.

Pachler, Norbert; Cook, John; Bachmair, Ben (2010). Appropriation of Mobile Cultural Resources forLearning. International Journal of Mobile and Blended Learning 2(1), 1-21.

Parry, Jane (2006). People with multiple disadvantages. In Carmen Leccardi \& Elisabetta Ruspini (Eds.), New youth? Young people, generations and family life. Aldershot: Ashgate. 276-297.

Preece, Jenny; Maloney-Krichmar, Diane (2003). Online Communities: Focusing on sociability and usability. In Julie A. Jacko \& Andrew Sears (Eds.), Handbook of Human-Computer Interaction. Mahwah: Lawrence Erlbaum. 596-620.

Swadener, Beth Blue; Lubeck, Sally (1995). The Social Construction of Children and Families «at risk»: An introduction. In Beth Blue Swadener \& Sally Lubeck (Eds.), Children and Families «at promise»: Deconstructing the discourse of risk. New York: State University of New York Press. 1-16. 
Wagner, Ulrike; Gerlicher, Peter; Gebel, Christa (2008). Ressourcenorientierte Zugänge zum Medienhandeln von bildungsbenachteiligten Heranwachsenden. In Ulrike Wagner (Ed.), Medienhandeln in Hauptschulmilieus: Mediale Interaktion und Produktion als Bildungsressource. München: kopaed. 19-56. 